\title{
PLANO DE MARKETING PARA A ASSOCIAÇÃO CRIANÇAS ESPECIAIS DE SANTA BRANCA ANTONIO NARVAES - (CESB)
}

\section{Lorena Gabriela Miranda de Castilho' Nayara Cristini Rodrigues ${ }^{2}$ Solange Donizete Batelli dos Santos ${ }^{3}$}

Resumo: O Plano de Marketing pode ser entendido como um documento a qual estão detalhadas as ações necessárias para se atingir um ou mais objetivos na área do marketing. O propósito deste trabalho é elaborar um projeto para a Associação Crianças Especial de Santa Branca (CESB), a fim de desenvolver uma comunicação adequada, por meio de estratégias e procedimentos que caracterizam a divulgação, para que a entidade seja capaz de informar as necessidades para o público alvo e assim, consequentemente, desenvolver soluções pertinentes, para que esta alcance seus objetivos referente a oferecer atendimento clínico, incluindo práticas educativas. A partir disso, foi realizada uma pesquisa de campo nos municípios de Santa Branca/SP, Jacareí/SP e São José dos Campos/SP, onde ressaltou-se uma deficiência em relação à divulgação, gerando uma dificuldade de arrecadação para a associação, tanto de voluntariado como de verba financeira.

Palavras-chave: Associação; Divulgação; Plano de Marketing.

\footnotetext{
${ }^{1}$ Administração/Colégios Univap Villa Branca, Brasil. E-mail: lorenagab2008@hotmail.com.

${ }^{2}$ Administração/Colégios Univap Villa Branca, Brasil. E-mail: na-yara.2009@hotmail.com.

${ }^{3}$ Professora Especialista Cordenadora/Univap Villa Branca, Brasil. E-mail: sbatelli@univap.br.
} 